\title{
Drastic effects of Climate Change on Mediterranean marine forests
}

Jana Verdura ${ }^{1}$, Alba Verges ${ }^{1}$, Jorge Santamaria ${ }^{1}$, Sonia de Caralt ${ }^{1,2}$, Enric Ballesteros ${ }^{2}$, Emma Cebrian ${ }^{1}$

${ }^{1}$ GRMAR Institute of Aquatic Ecology, University of Girona, Girona, Catalonia, Spain

${ }^{2}$ Centre d'Estudis Avançats de Blanes, Consejo Superior de Investigaciones Cientificas, Blanes, Catalonia, Spain

Corresponding Author:

Jana Verdura ${ }^{1}$

E mail address: jana.verdura@udg.edu 


\section{DRASTIC EFFECTS OF CLIMATE CHANGE ON MEDITERRANEAN MARINE FORESTS}

Verdura, J. ${ }^{1}$, Vergés, A. ${ }^{1}$, Santamaria, J. ${ }^{1}$, de Caralt, S. ${ }^{1,2}$, Ballesteros E. ${ }^{2}$ \& Cebrian, E. ${ }^{1}$

${ }^{1}$ GRMAR Institute of Aquatic Ecology, University of Girona, Girona, Catalonia, Spain

${ }^{2}$ Centre d'Estudis Avançats de Blanes, Consejo Superior de Investigaciones Cientificas, Blanes, Catalonia, Spain

Macroalgal forests have gone missing from most temperate rocky shores during the last decades, triggering an important biodiversity loss. Cystoseira species are some of the main marine habitat-forming species on shallow water Mediterranean rocky bottoms and follow the same tendency, mainly related to habitat destruction and pollution. However, here we suggest that anormal positive thermal events may contribute to this widespread Cystoseira decline. Monitoring thorough natural populations showed a drastic decline on a natural and relict $C$. crinita population in terms of density and structure coinciding with anormal high temperatures experienced during a summer period. Additionally, we experimentally test in the laboratory the cause-effect of those temperatures and UV radiation conditions experienced in the field on $C$. crinita populations. Although, $C$. crinita is able to resist high temperature picks, usually reached in Mediterranean summers, exceptional and maintained periods as those experienced during extreme events $\left(28^{\circ} \mathrm{C}\right)$ lead to the death of all individuals, compromising the viability and conservation of these forest-forming populations. We show how climate change may seriously compromise algal populations and synergically act with historical drivers of macroalgal decline (pollution, habitat destruction and herbivorism). 
Financial support from EU2020 (R+I) under grant agreement No 689518 (MERCES), MINECO (CGL2016-76341-R) and from University of Girona under congress assistance fellowship program for PhD and master students. 
(c) 2018 Verdura et al. This is an open access article distributed under the terms of the Creative Commons Attribution License: http://creativecommons.org/licenses/by/4.0/ (the "License"), which permits unrestricted use, distribution, reproduction and adaptation in any medium and for any purpose provided that it is properly attributed. For attribution, the original author(s), title, publication source (PeerJ Preprints) and either DOI or URL of the article must be cited. Notwithstanding the ProQuest Terms and Conditions, you may use this content in accordance with the terms of the License. 